Silver, Curdt-Christiansen, Wright and Stinson

Working through the layers

\title{
WORKING THROUGH THE LAYERS: CURRICULUM IMPLEMENTATION IN LANGUAGE EDUCATION
}

Rita Elaine Silver, Xiaolan Curdt-Christiansen, Susan Wright, Madonna Stinson

\section{INTRODUCTION}

Singapore is well-known for its global economic outlook coupled with locally oriented political and social policies. From the early days in Singapore's history, economic goals were grounded in international trade due to Singapore's limited material resources to turn into manufacturing strength. Instead, the intention was to build a cohesive social structure out of the post-colonial multicultural, multilingual citizenry which could then be leveraged for economic development (see, e.g. Silver 2005). This led Singapore to take a global view of development before 'globalisation' became the buzz word of the moment in that Singapore made a concerted effort to build capacity internally by capitalizing on international trade networks. The idea of leveraging the skills of the citizenry led naturally to concern for educational policy. Three important policy goals from the early days of Singapore's nationhood and continuing into the present were:

- to design and maintain a national school system with a common syllabus and national examinations;

- to emphasise broad-based education at the primary school level, then progressively develop and strengthen education through levels of higher education which offer different pathways for students of different abilities and interests; 
Silver, Curdt-Christiansen, Wright and Stinson

Working through the layers

- to implement an English-knowing bilingual education policy with provision for a role for one official language for each ethnic group (Chinese, Malay, Tamil) plus English for all students as part of the core curriculum.

Historical developments linking economy, education, and language have been well covered elsewhere (e.g. Gopinathan 1997, 2001; Silver 2005). Of importance for this discussion is that policies aimed at improving economy-education-language linkages are a significant contributing factor to long-standing, on-going curricular innovation in Singapore. Within the broader socio-political environment, the educational landscape is managed through a central governing body which sets system-wide goals and policies (e.g. language education policies) intended to integrate with larger national goals, as well as establishing standards for learning outcomes and high stakes assessments. However, the system is decentralised at the local level (schools, school departments) where responsibility for interpreting the goals and standards, preparing students for high stakes assessment, implementation and evaluation of learning outcomes resides (Tan and Ng 2007). Curriculum development and innovation links national, school and classroom levels with different ideological and practical concerns influencing potential innovators at each level in Singapore (Towndrow, Silver and Albright 2010) and elsewhere (see Honig 2006, for discussion). With that in mind, this chapter presents findings on English Language (EL) instruction at the lower primary level in the context of policies of curricular innovation at national, school and classroom levels. Our focus is on policies which connect national and school levels and on how they might be interpreted when implemented in multiple schools within Singapore’s educational system. 
Silver, Curdt-Christiansen, Wright and Stinson

Working through the layers

\section{LANGUAGE POLICY, EDUCATIONAL INNOVATION AND CLASSROOM \\ PEDAGOGY}

Singapore's achievements in economic development, educational attainment and bilingualism in the official languages are substantial and well-documented (see, e.g. Singapore Department of Statistics 2011). However, Singaporean policy makers, rather than resting on the country's laurels, prefer to continually push for further development and improvement. Hence the constant emphasis on curriculum innovation and renewal. This is evident in the Thinking Schools Learning Nation (TSLN) 'vision’ which sets its sights on enhanced capacity through innovation, enterprise and life-long learning. Specifically, the TSLN vision encourages upgrading as a nation, through continued economic development, job training throughout the career span, as well as continuous improvements in education in schools (Goh 1997). For schoolbased education, TSLN envisions a 'global future' with schools which are more autonomous, teachers who are reflective and continuously involved in professional development and students who have a passion to learn (ibid).

Following up on the TSLN vision, Prime Minister Lee Hsien Loong called for ways for teachers to "teach less, so that our student can learn more" (MOE 2005: para. 2) leading to the 'Teach Less, Learn More'(TLLM) initiative which emphasises the need "to improve the quality of interaction between teachers and learners" (para. 3) in order to encourage students to learn more actively and independently. Continuing the ideas introduced with TSLN but specific to schooling, TLLM acts as an umbrella under which a variety of educational reform efforts have been initiated (Figure 1)—all in keeping with the idea that Singaporeans must be grounded in local values but educated for participation in a globalised society. 
Silver, Curdt-Christiansen, Wright and Stinson

Working through the layers

Among the initiatives associated with TSLN and TLLM is Curriculum 2015 (C2015)

which focuses, in particular, on the anticipated skills and competencies a child born in 2014 might need by the time of graduation and entering the workforce, and the implications of those needs for educational reform today. Other initiatives include SAIL (Strategies for Active and Independent Learning), SEED (Strategies for Engaged and Effective Development), and PETALS (Use of Pedagogies, Experiences of Learning, Tone of Environment, Assessment for Learning, and Learning Content) which are intended to influence education from primary grade 1 through primary grade 6 (P1-P6), across subjects. Still others, such as TLLM Ignite!, focus on professional development in light of TLLM.

In addition, some policy initiatives are targeted specifically at lower primary with the idea that initial stages of education are crucial for future educational achievement. Class size reduction for P1 and P2 (from 40 to 30 students) is one recent example. Other initiatives are subject specific. Recent EL reform efforts include a curriculum and pedagogy review, syllabus revision, the establishment of ELIS (English Language Institute of Singapore) for teacher professional development, and the introduction of the STELLAR (Strategies for English Language Learning and Reading) curriculum. Most recently the Primary Education Review and Implementation (PERI) review was completed. The PERI report (PERI Committee 2009) made three main recommendations: enhance infrastructure; invest in a quality teaching force; and balance knowledge with skills and values in a whole-school curriculum, all of which MOE is now acting on. This sample of reform initiatives (see Appendix A for weblinks to each) indicates Singapore's constant attempts to push educational reform forward, always with an eye toward 
Silver, Curdt-Christiansen, Wright and Stinson

Working through the layers

the anticipated needs of the $21^{\text {st }}$ century workforce and a perspective of globalisation at the heart of those needs. As noted by Ng Eng Hen, Minister for Education,

To an observer, MOE and our schools are constantly on the move. Even when we have attained high standards, we are still seeking to improve. There is a reason for this unabating activity. The many changes across decades, different ministers, different administrators, do have continuity in purpose and motivation. There is a melody that runs through and a motif that keeps on recurring. Very simply, we treasure our human resource as the most valuable asset in Singapore (2008: para 7).

Policy making tends to be heavily top-down in Singapore with a variety of policies initiated by the MOE. However, not all policies are intended to be implemented with uniformity across the nation. Instead, some policies are intended to be developed on a whole-school basis and some are intended to encourage initiative by teachers in individual classrooms. For example, the ICT Masterplan, now in its third iteration, has fostered nation-wide upgrading of ICT equipment including most recently the introduction of a wireless network that students can tap into while at school (Lim 2010). However, individual schools have a choice of how and in what ways to integrate ICT in learning. For example, a few school have moved toward whole-school student laptop adoption while others maintaining more traditional computer labs. In all schools, teachers and students have access to MOE sponsored websites for online learning which teachers can choose to assign as homework, suggest as supplementary work, or disregard in setting assignments. Thus different policies work at one or more layers of implementation: national, school, and classroom. 
Silver, Curdt-Christiansen, Wright and Stinson Working through the layers

To examine the issue of how the education system nurtures its most valuable assets, children, we were interested not only in providing summary descriptions of classroom pedagogy, but also in presenting the voices of those educators engaged within and across the different layers of innovation in order to better understand the broadest range of perspectives possible. This lead us to ask two key research questions:

1. How are these policies and innovations interpreted and implemented across layers (i.e. national, school, class)?

2. To what extent and in what ways, are they visible in classroom pedagogy?

\section{Data Sources and Analyses}

For this investigation, we adopted a multi-method approach including a case study of P2 instruction undertaken at two schools and individual lesson observations done at 10 schools in the same administrative 'zone' ${ }^{1}$ in Singapore. The combination of case study and individual lesson observations provided opportunities to address implementation processes horizontally and vertically across layers (e.g. national, school, classroom) and in multiple sites.

The case study component (CSC) followed two classes of students and their form teachers for two periods of five full days. It also included interviews with school leaders and classroom teachers, as well as focus group discussions with parents. In contrast to the intensive investigation in the CSC, the lesson observation component (LOC) emphasised examination of individual lessons at P1 and P2 in 10 schools, using a pre-determined coding scheme. A total of 19, one-hour, EL lessons were observed for the LOC. To gain some context for the individual

\footnotetext{
${ }^{1}$ There are four geographic zones in Singapore: North, South, East and West.
} 
Silver, Curdt-Christiansen, Wright and Stinson

Working through the layers

lesson observations, we included brief pre-observation interviews with each teacher (e.g. "Is this a topic you have been teaching or is this the first lesson on this topic?"). Follow-up interviews with a sub-set of 7 teachers were also undertaken to provide a glimpse into the teachers' perspectives and beliefs (c.f. Borg 2006). In these interviews, teachers watched a video recording of their own lessons with a researcher, and offered spoken reflections while viewing. Thus, the lesson observation component provided a basis for comparative analysis with the more detailed CSC. All data were collected from Terms 3 and 4 of the academic year (July - December) of 2009. Detailed descriptions of data collection instruments and protocols can be found in Stinson, et al. (2010).

For the CSC, field notes from observed lessons along with transcribed interviews and parent focus group discussions were analysed using the framework of content analysis (Berg, 2004). Emerging themes were identified by looking for ideas which surfaced repeatedly in the data and/or comments about known policy initiatives (e.g. alternative assessment, STELLAR, ICT). The data were coded by one trained Research Associate and one trained Research Assistant under the guidance of the Principal Investigators. Rather than coding independently and calculating inter-coder agreement as with frequency analyses, these data were initially coded collaboratively to surface emerging themes. Subsequently, when the team had agreed on important themes to be traced, the two RAs coded the lessons which they had observed. Then, the entire set of data and codes were re-checked through iterative readings. In this way, patterns in the analysis were confirmed, disconfirmed and finalised.

In contrast, analysis of LOC data was intended to facilitate comparison of the individual lessons, provide a normative overview of EL lessons at P1 and P2, and allow for the expression 
Silver, Curdt-Christiansen, Wright and Stinson

Working through the layers

of individual teacher's perspectives via post-observation interviews with a subset of teachers.

Coding was done within the context of a larger study which looked at core subjects (EL, maths,

Mother Tongue) in P1 and P2. (See Silver, et al. 2011, for details of the larger study.) Inter-coder agreement was verified using a sub-set of six English and four Math lessons (27\% of the total observations for those two subjects), checking for pair wise inter-coder agreement with a 'master coder' - a Research Associate who helped to develop the coding scheme (Silver, Pak and Kogut 2010). Agreement for English lessons was above 80\% overall which was deemed to be sufficient for our purposes. Subsequently, coding across lessons was collated to establish common classroom patterns. A total of 7 EL teachers were intereviewed from the LOC. These interviews were coded using the categories derived from the CSC. Specifically, the Research Associate who was involved in the analysis of CSC data subsequently coded the teacher interviews for the LOC, using the same themes where appropriate and noting new themes as needed.

Finally, data from both CSC and LOC were synthesised according to the three levels in which the policies are intended to operate in the Singapore system: national policies promulgated by the MOE, school policies instituted by the individual school, and class policies developed by the teacher. Overall findings were generated by moving recursively between CSC and LOC to synthesise pertinent themes at the three levels. Our findings are drawn from that synthesis.

\section{WORKING THROUGH THE LAYERS}


Silver, Curdt-Christiansen, Wright and Stinson Working through the layers

In this section we summarise our findings, referring to both CSC and LOC. We integrate information from the classroom observations and interviews to address issues of implementation and interpretation within and across layers: national, school and classroom.

\section{National Policies}

First, a number of national policies were familiar to school leaders and classroom teachers alike. Some of these same initiatives were also mentioned by parents in focus group discussions at the case study schools. However, other national policies seemed to be relevant only to school leadership and were not apparent in classroom lessons or teacher interviews. Two area of national policy were most evident in attempting to influence classroom pedagogy: 1) administrative reforms such as the implementation of 'single sessions' and related opportunities for changes in the classroom physical environment, and 2) introduction of a new English curriculum (STELLAR) coupled with school-based professional development.

\section{Administrative Reforms}

Cohen and Ball define innovations as “... a departure from current practice - deliberate or not, originating in or outside of practice, which is novel” (2007: 19). They discuss educational innovations in light of who innovates, types of innovations, and environments for innovation, noting that innovations need not directly target instruction. Administrative reforms are one type of innovation which can intentionally or unintentionally influence pedagogy. In Singapore, a few recent administrative reforms have been initiated as intentional efforts to encourage instructional change. One is the shift to single-session schools. 'Single sessions' refers to the way school 
Silver, Curdt-Christiansen, Wright and Stinson

Working through the layers

facilities are scheduled for teaching. Previously, schools scheduled a 'morning session' and an 'afternoon session' at each school. Students attended one or the other, thus allowing for 'double sessions' in one school building and maximising the use of the facilities. The downside of this arrangement, as noted by the PERI report (PERI Committee 2009: 47-49), was that it discouraged more holistic education as well as limiting opportunities for meaningful interaction between students and teachers. The educational system has been moving toward single sessions since 2004 and all schools are to convert to single-session by 2016. This has already been implemented in many of the schools in the LOC as well as one of the case study schools.

In general, the move toward single-session was viewed positively by school leadership and teachers. One teacher who was still at a double-session school commented, "Personally, I'm looking forward to having a single session for our school." Parents were quite enthusiastic as well saying, "I like it!" and "I’m all for it" with only one parent demurring that school facilities might be too cramped if all of the children tried to fit into the school for single session. However, specific comments on the change to single sessions were related to changes in the physical environment rather than opportunities for holistic education, meaningful student-teacher interaction or classroom pedagogy. In our lesson observations and school visits, we found that teachers had taken advantage of the classroom ownership allowed by single sessions to decorate their P1/P2 classrooms with colorful literacy prints and displays of student work. Arrangements for group seating were also common in P1/P2 classrooms at these schools. In contrast, teachers in double sessions schools had to compromise on classroom design due to sharing by different grade levels in the other session. 
Silver, Curdt-Christiansen, Wright and Stinson

Working through the layers

Teacher efforts to improve the physical environment were in accord with SEED and STELLAR philosophies on increasing student interest and engagement through physical changes intended to enhance the socio-emotional environment of classrooms. However, there was no evidence that these physical changes influenced teacher pedagogy, student learning or interactions in daily lessons. For example, the literacy prints and student work were not referred to in any of the observed lessons; and, while students were seated together, they very rarely worked together. Instead, lessons were heavily whole-class, 'eyes on the front', teacher-led. Students appeared 'engaged' in the sense that they were largely on-task and compliant. There was little evidence of cognitive or affective engagement in student questions, comments or responses (Curdt-Christiansen and Silver in press; Silver, et al. 2011), so the quality of engagement in the learning process is open to question. Our 2009 classroom data mirrored findings summarized by Deng and Gopinathan (1999):

In most classrooms teachers tend to dominate most instructional discourse: teachers see their role primarily as transmitting knowledge and skills to students through didactic telling, explaining, and some limited doing, while students are expected to absorb knowledge and skills through passive listening, watching, drilling, and practising (p. 34). Deng and Gopinathan follow this description with a suggestion for change in professional development, noting that, "reform in professional development must act together, not in isolation, with other innovations and developments" (37). The reverse is self-evident—curriculum innovation must work together with reform in professional development.

Curriculum Reform Coupled with Professional Development 
Silver, Curdt-Christiansen, Wright and Stinson

Working through the layers

On-going efforts in professional development link national and school-based reform efforts. For example, several teachers mentioned that they had received formal training for the new STELLAR curriculum through MOE workshops. They also worked with a STELLAR mentor, an MOE staff member, in their own schools. In a few of the schools, individual teachers had not received formal STELLAR training but an in-school mentor provided guidance. Thus, curriclum reform and professional development were intended to work together, crossing national and school levels to encourage implementation in the classroom. To some extent, this was successful as our lesson observations showed substantial uniformity across all EL lessons at the different schools.

While this consistency speaks well for the uptake of STELLAR and the effectiveness of the professional development, it also suggests that school-based curriculum was simply superimposed onto the more structured, MOE initiative. Specifically, most of the teachers in the observed lessons used a recommended STELLAR technique (Share Book Approach), with books and materials provided by MOE. They rigorously followed the detailed lesson plans that accompanied the materials, consistently using questions and prompts taken from the lesson plans. While a current concern is more differentiated learning, the structured approach to introducing STELLAR instead lead to an homogenised pedagogy. Uniformity is expected in a centralised system such as Singapore's, but rote replication of lesson plans is not ideal.

Based on the observational data, there is some concern that the implementation of STELLAR resulted in surface level changes (i.e. teachers prioritising the lesson plans) rather than a reflection of deeper understanding (i.e. teachers engaging with pedagogical principles of 
Silver, Curdt-Christiansen, Wright and Stinson

Working through the layers

engagement such as enjoyment or on-task behaviour) ${ }^{2}$ (Curdt-Christiansen and Silver 2011) at least in these initial stages. For example, one teacher while watching her lesson video commented, "This is er one of the, the just following the STELLAR...like re-reading, then tuning in, then re-reading, and then lesson proper." Interestingly, while STELLAR guidelines stress the importance of re-reading to develop reading comprehension, for this teacher, that pedagogical strategy was superfluous to the real work, the "lesson proper" (i.e. the teacherfronted content). Nevertheless, she followed through because she believed that following the steps of the lesson plan was equivalent to implementing the curriculum.

Rigid following of the lesson plan, in fact, contradicts the spirit of STELLAR, which is intended to encourage teachers "to adapt and innovate to suit the needs of their students" (MOE 2008b). A Senior Teacher mentioned that her school modified STELLAR by adding their own 'skill-based’ worksheets, and one teacher stated categorically that "STELLAR is good but you must tailor it to the needs of the children in your class." Another teacher explained that

The whole basis of this STELLAR is that we are given a very standard and specific set of guidelines to follow. So as far as possible, the teachers would have to follow strictly to the guidelines in order for that particular topic or unit to be completed on time. Because there will, I mean, there will be checking, and things like that so in a way I would say that $60 \%$ of what the teachers in the level are doing are all the same because they are all following the guidelines but the other $40 \%$ it would depend on the teacher like maybe they would supplement with their own worksheets, or they might just change a little bit of the language experience, like for example, let's say the current topic that I'm doing. I got my kids to

\footnotetext{
${ }^{2}$ See Silver, et al. (2010) for discussion of coding for student engagement in observational studies.
} 
Silver, Curdt-Christiansen, Wright and Stinson

Working through the layers

make percussion instruments, er, and then just shakers, and I got them to do a dance but another class might do it differently. Like they will get them to do hmm percussion instruments or they might hold a mini competition to see like whose instrument is the most creative, things like that. (Sheila, P2 teacher) ${ }^{3}$

However, our lesson observations in the case study schools and across all 19 lessons of LOC showed higher than $60 \%$ uniformity in lesson content and activity selection. Instead we observed a consistent twin emphasis on the authority of the packaged lessons plan over teacher curricular expertise and on tight interactional control by teachers over the sort of dynamic classroom interaction and development of independent student learners espoused by TLLM, C2015 and PERI (Curdt-Christiansen and Silver 2011; in press).

\section{School Policies}

School-level policies followed national reforms, acting as the mediating layer between national initiatives and classroom innovations. This was particularly evident in the crucial area of assessment and in the ways assessments were linked to student placement. National policy encourages ‘streaming’ or performance-based placement throughout the broader educational system. This is done through national examinations such as the Primary School Leaving Examination (PSLE) which all students are required to take in P6. Scores from the PSLE influence the selection of secondary school and several other choices in secondary education, such as whether the students will study 'sciences' or 'humanities'. Within the primary grades, current national policy recommends ‘subject-based banding' so that students who excel in

\footnotetext{
${ }^{3}$ Teacher names, where used, are pseudonyms.
} 
Silver, Curdt-Christiansen, Wright and Stinson

Working through the layers

Mother Tongue but are weaker in English, for example, can be banded according to their strengths for each subject rather than taking all courses with the same classmates based on averaged scores. In our sample, most schools implemented subject-based banding at P2 but a few introduced it in P1.

Formal Examinations and 'Alternative' Assessments

Examinations play an important part in determining a student's placement for the next year, despite continued efforts to introduce more alternative assessments (e.g. use of show-andtell rather than a pencil-and-paper examination). All of the schools in our sample had formal examinations from P1 onwards and the results were a substantial part of banding decisions. However, there was variation from school to school in the way formal exams were implemented, when they were given and for which subjects. While some schools had a special end-of-term exam timetable, others had started to introduce exams following the regular class timetable. Also, some schools had moved toward reducing or doing away with formal examinations at the end of every term (4 per year) and instead opted for these sorts of exams only at the end of the mid-year and final semesters. All schools had introduced some 'alternative' assessments such as regularly scheduled class tests, scoring homework as part of the overall course marks, or use of classroom presentations scored with rubrics for a percentage of the total marks each term. Despite the introduction of these alternative assessments, there was an enduring belief in the importance of formal examinations. Even the way activities were managed in class was influenced by formal examination structure and requirements. Comments such as "Because this is in accordance to examinations" or "Because, say for example, reading alone, accounts for 20 marks [on the 
Silver, Curdt-Christiansen, Wright and Stinson

Working through the layers

exam]" were common in teacher interviews. As one teacher emphasised "Because all will go back, in the end all will go back to sitting there, to take exams without complaining."

Yet, the PERI report encourages "schools to move away from an overly strong emphasis on examinations" and to begin exploring "the use of bite-sized forms of assessment which place more emphasis on learning rather than on grades alone" (35). Some schools were moving toward this goal more quickly than others. In the case study schools, for example, one school had started to implement alternative forms of assessment rather than relying on formal examinations at P2, while the other school was still planning for the introduction of some form of alternative assessment. The fact that changes in assessment practices were open to dialogue showed that these were school-based decisions, influenced by national policy objectives, and gradually working their way into teachers’ decisions about classroom implementation.

\section{Classroom Policies}

Teachers frequently referred to MOE initiatives which influenced their teaching. This linkage was particularly common when discussing assessments and the introduction of STELLAR. Teachers also commented on how school leadership had worked to implement these initiatives school-wide. Thus, a connection between national policy and classroom practice with mediation at the school level was evident.

Following Policy

Speaking specifically about STELLAR, Chris, a P2 teacher, said, 
Silver, Curdt-Christiansen, Wright and Stinson

Working through the layers

So basically most of the time I follow, I refer to the guidelines to help me with the lesson. And it's quite helpful because er the fact that there's group work and um, there's actually written work for them to do after the group work. It actually helps them put two and two together.

Viewing group work less positively but still 'exploring' its use because it was supported by the school and MOE, Nurliza, a P1 teacher said:

So they, the principal, or the MOE, doesn't want us to sit in rows like this. Um. So we'll try our best to make them [students], move around. So one advantage of moving about is that they will like this very much. Then its disadvantage is, very noisy, bad classroom management. This is what I have always been exploring.

There seemed to be a certain trust between teachers, schools and those working at the national level which helped to strength the connections between national-school-classroom policies. One Head of Department (HOD) articulated this explicitly, "... with STELLAR, everything is systematic ... And the fact that it's a direction from MOE, and thought has been gone through, has gone into it, we kind of knew that there must be substance in it." However, she went on to say "I first had to tell, sell them [teachers] STELLAR. And kind of went through it with them, er, what STELLAR is about, and like I said they were very excited about it. I guess to get anything moving there must be buy-in.” For teachers, it is important to see innovation as relevant to their own concerns. For example, a number of teachers commented that fewer formal assessments in P1 and P2 were appropriate and 'going in the right direction' and so they were working to introduce the 'alternative' assessments described above, despite some continuing concerns about assessments in general. 
Silver, Curdt-Christiansen, Wright and Stinson

Working through the layers

\section{Adapting Policy}

Although there are many national reforms implemented in top-down fashion, with mediation at the school level, it would be incorrect to leave the impression that teachers were thoughtlessly following a path laid out by others. As in the quote from Nurliza above, although she was not always comfortable with the new physical arrangement, she was considering both pros and cons and exploring how to work with it. Use of group work was one area in which opinions differed and teachers often followed their own perceptions rather than external recommendations. Group work and social interaction are emphasised in the PERI report, suggested for some STELLAR activities, and recommended for some alternative assessments. In our data, a few teachers used group work throughout a lesson, but the majority used group work not at all. Teachers felt free to make modifications in types of activities, introduction of materials and tools (e.g. videos, puppets, songs, dances), and selective omission of some worksheets. One teacher explained:

STELLAR is good but you must tailor it to the need of the children in your class. So, there must be freedom, for example, like Class A, the best class can do six books in one term. OK, fine, go ahead. But Class $\mathrm{H}$ is not as fast as them, you must tell them, OK no problem. As long as you read the book with them. But, you know, if the grammar item is covered already in the previous term ... there is no point in it.

Teachers were most likely to make adaptations that they felt were important for specific groups of students, usually because of their 'ability level'. However, these were small-scale changes in classroom practices.

Leading Policy 
Silver, Curdt-Christiansen, Wright and Stinson

Working through the layers

Teachers appeared to be leading policy innovations in one area—the teaching of values and social skills. This was clearly apparent in classroom lessons and teacher interviews, yet it rarely came up in discussions with school leaders and was not a dominant theme in national policies at the time of data collection. A few teachers were quite explicit about what was appropriate and inappropriate during lessons; others broached the teaching of values through their use of instructions for activities to be undertaken or in their feedback on student behaviour and ideas (especially for social skills such as sharing or working together). The teaching of moral values was especially evident in the discussions of stories, with many teachers noting that they intentionally brought out the moral values implicit in the stories read during lessons. In addition, teachers were exceptionally reflective about their own efforts to bring the teaching of values into a lesson. For example, while viewing her own lesson, one teacher explained that she was teaching the students about the importance of sharing while reading the story The Little Red Hen. On reflection, she was not completely satisfied with her own treatment of the subject, recognizing that the performance of values might need to be more nuanced in daily life.

But urm there was one area I feel I should improve on. It's that beside telling ya the children suggested that the urm the red hen could share but I must also bring across the fact that urm you have to urm earn your own, work for your own... You cannot let people take advantage of you at the same time...Which I didn't drive across. And then I went back and think about it ya I feel that I should have said something so so that the children will not be misled that every time you know people ask me I'm obliged to do it. (Shih Fen, P2 teacher) 
Silver, Curdt-Christiansen, Wright and Stinson

Working through the layers

In their integration of values into daily teaching, the teachers foreshadowed the latest wave of policy reform as introduced by the Minister of Education, Heng Swee Keat at the annual Workplan Seminar for Singaporean educators in 2011. Minister Heng focussed on moral values in education saying,

We need moral values, such as respect, responsibility, care and appreciation towards others, to guide each of us to be a socially responsible person. In particular, for our multiracial, multi-cultural society, a sense of shared values and respect allows us to appreciate and celebrate our diversity, so that we stay cohesive and harmonious. (2011: para 41) We note that in these comments, Minister Heng echoes earlier, and consistently used, arguments for linking economic development, education and social cohesion.

\section{Conclusion}

Given the close links between national policy setters at MOE, school leadership and teachers, it is not surprising that national policies have influenced classroom teaching in ways that closely align with those initiatives. In their analysis of 'implementation' of National Curriculum policy in the UK. Ball and Bowe discuss the re-interpretations of policy at different levels of enactment, highlighting the multiple factors that can influence how policies are 'recreated' rather than 'implemented' (1992: 113-114). For example, they point out the crucial role of HODs in making sense of change at a school and with colleagues. In our data, various school leaders (e.g. Principal, Senior Teacher) could and did provide the necessary leadership for implementation of new policies. However the new STELLAR curriculum was also supported by 
Silver, Curdt-Christiansen, Wright and Stinson

Working through the layers

MOE staff who offered training and in-school mentoring. This is certainly one factor in the great uniformity of classroom lessons under STELLAR.

Ball and Bowe (1992) also point out conflicts around funding, staffing and assessment only some of which were visible in our data. For example, they found problems in unequal resource distribution to their case study schools which had a carry-on effect in implementation. This was not an issue in the schools in our sample, all of which were well-funded. The schools in Singapore were also fully staffed, although there were concerns about new and inexperienced teachers trying to carry out new initiatives. As one HOD explained, in her school only the P1 teachers received MOE training and there was concern that lack of expertise would negatively influence the introduction of the curriculum. Therefore, they offered in-school training with a buddy system. These sorts of 'innovations' highlight the important mediating influence of the school in the implementation plan, as discussed above. Concerning assessments, national assessments were viewed negatively by teachers in Ball and Bowe's study, but these have always been the norm in Singapore. In fact, it seems that schools now have somewhat more autonomy in deciding assessment timing and type in these early years, though they are still concerned about and constrained by the national PSLE, as above.

On the other hand, adoptions and adaptations of policy innovations at the classroom level were somewhat superficial: they were more related to changes in educational facilities and procedures than in philosophies. We found, for example, that even though there was wide-scale adoption of STELLAR teaching materials and strategies, lessons were tightly structured with predominantly teacher-fronted interactions (Curdt-Christiansen and Silver 2011). These areas are 
Silver, Curdt-Christiansen, Wright and Stinson

Working through the layers

more resistant to change because they are more closely linked to teacher beliefs and cultural values than to procedures and programmes.

It is also true that there was little evidence of policy initiation or curriculum innovation at the classroom level. Although school leaders and teachers felt it was important to let teachers adapt ways of presenting the curriculum, this is not the same as teacher-initiated school-based curriculum development to address specific school goals or student learning objectives. In addition, classroom instruction continued to prioritise examinable subjects over holistic education, and formal assessments over other measures of learning, even in the first two years of primary school. Finally, despite multiple initiatives to encourage the TSLN vision of students with a passion to learn as well as efforts to improve the quality of classroom interaction under the auspices of TLLM, we saw lessons which were well-planned and well-managed, but rarely encouraged passionate pursuit of knowledge, higher-order thinking or open-ended interaction. This leaves the door open for further reform efforts, and raises the question of whether the same types of reform efforts are the way forward.

Innovation, engagement and a futures orientation to teaching and learning are persistent themes in the many policy innovations introduced at the national level. To foster further innovation, Ng (2004) has suggested that schools adopt an organisational change model in order to reflect upon and evaluate their own innovation journey. In such a change model, leaders and teachers within each school would need to consider their own innovation objectives ('goals'), the programmes they wish to propose ('business'), the mindset and beliefs of people in the school ('culture'), the workflow to achieve the proposed programmes ('processes'), and the resources and tools that are needed ('enablers'). This makes sense in light of our view that the school acts as the 
Silver, Curdt-Christiansen, Wright and Stinson

Working through the layers

mediating layer for national policies and classroom implementation. However, it does not fully take into account the way schools adopt national policies. National leaders, such as former Minister of Education Ng Eng Hen, might see the common melody and recurring motif of policy innovations, but schools and teachers often become more focused on dancing to the latest tune. An alternative view is that the next stage in educational innovation should not be based on asking, "How do we encourage teachers to innovate?" but "What sorts of innovations do teachers see as necessary and useful, within their schools, and for their students' future?"

\section{Acknowledgements}

We gratefully acknowledge funding by the Office of Educational Research, National Institute of Education, Singapore. The views expressed in this paper are the authors' and do not necessarily represent the views of the Centre or the Institute. We would also like to acknowledge Peter Taylor for the training sessions on content analysis and focus group discussions and express our appreciation to our research team:

- Cai Li

- Wartik bte Hassan

- Alamu Venkatachalam

- Tan Ying Quan

- Santhakumari d/o N. Krishnan

Finally, we offer our sincere thanks to the study participants—students, teachers, parents and school leaders—-for their time and efforts on behalf of the project.

\section{References}


Silver, Curdt-Christiansen, Wright and Stinson

Working through the layers

Ball, S. \& Bowe, R. (1992). Subject departments and the 'implementation' of National Curriculum policy: an overview of the issues. Journal of Curriculum Studies, 24(2), 97115. doi:10.1080/0022027920240201.

Berg, B. L. (2004). Qualitative research methods for the social sciences (5th ed.). Boston: Pearson.

Borg, S. (2006). Teacher cognition and language education: Research and practice. London: Continuum International Publishing Group.

Cohen, D. K., \& Ball, D. L. (2007). Educational innovation and the problem of scale. In B. L. Schneider \& S.-K. McDonald (Eds.), Scale-up in education: Ideas in principle, Vol. 1 (pp. 19-36). Plymouth: Rowman \& Littlefield.

Curdt-Christiansen, X.-L., \& Silver, R. E. (in press). Educational reforms, cultural clashes and classroom practices. Cambridge Journal of Education.

Curdt-Christiansen, X.-L., \& Silver, R. E. (2011). Learning environments: The enactment of educational policies in Singapore. In C. Ward (Ed.), Language Education: An essential for a global economy (pp. 2-24). (RELC Anthology, \#52). Singapore: SEAMEO, Regional English Language Centre.

Deng, Z. \& Gopinathan, S. (1999). Integration of information technology into teaching: The complexity and challenges of implementation of curricular changes in Singapore. AsiaPacific Journal of Teacher Education and Development, 2(1), 29-39.

Goh, C. T. (2 June 1997). Speech by Prime Minister Goh Chok Tong at the Opening of the $7^{\text {th }}$ International Conference on Thinking. Singapore: Suntec City Convention Centre. http://www.moe.gov.sg/media/speeches/1997/020697.htm

Gopinathan, S. (1997). Eduation and development in Singapore. In J. Tan, S. Gopinathan, and Ho Wah Kam (Eds.), Education in Singapore: A book of readings (pp. 33-54). Singapore: Prentice Hall.

Heng, S. K. (2011) Opening address by Mr Heng Swee Keat, Minister for Education, at the Ministry of Education (MOE) Work Plan Seminar. Singapore: Ngee Ann Pollytechnic Convention Centre.

Honig, M. I. (2006). Complexity and policy implementation: Challenges and opportunities for the field. In M. I. Honig (Ed.), New directions in education policy implementation : Confronting complexity (pp. 1-23). Albany: State University of New York Press. 
Silver, Curdt-Christiansen, Wright and Stinson

Working through the layers

Lim, T. S. (2010). Use of ICT in schools aimed at enhancing teaching and learning. Forum Letter Replies. Ministry of Education, Singapore. Available at http://www.moe.gov.sg/media/forum/2010/06/use-of-ict-in-schools.php

MOE. (2005). Teach less, learn more. Singapore Education Milestones 2004-2005. Available at http://moe.edu.sg/about/yearbooks/2005/teach.html

Ng, P. T. (2004). Innovation and enterprise in Singapore schools. Educational Research for Policy and Practice, 3(3), 183-198.

Ng, E. H. (2008). Speech by Dr. Ng Eng Hen, Minister for Education and Second Minister for Defence, at the MOE Work Plan Seminar, 2008. Ngee Ann Polytechnic Centre, Singapore. Available at http://www.moe.gov.sg/media/speeches/2008/09/25/speech-bydr-ng-eng-hen-at-the-moe-work-plan-seminar-2008.php

PERI Committee. (2009). Report of the Primary Education Review and Implementation Committee. Singapore: Mininstry of Education. Available at http://www.moe.gov.sg/media/press/files/2009/04/peri-report.pdf

Silver, R. E. (2005). The discourse of linguistic capital. Language Policy, 4 (1): 47-66.

Silver, R. E., Wright, S. K., Amasha, S. A., Abduallah, R., Curdt-Christiansen, X.-L., Lakshmi, S., Yang, Y., Yeo, J.K.K., Pak, S. (2011). Curriculum implementation in early primary schools in Singapore (CIEPSS). Final Report. Singapore: National Institute of Education. Available at: http://repository.nie.edu.sg/jspui/handle/10497/4453

Silver, R. E., Pak, S., and Kogut, G. (2010). Curriculum Implementation in Early Primary Schooling (CIEPSS): Coding scheme manual. Singapore: Centre for Research in Pedagogy and Practice, National Institute of Singapore. Available at http://repository.nie.edu.sg/jspui/handle/10497/2911

Singapore Department of Statistics. (updated 17 Feb 2011). Census of Population 2010 Statistical Release 1: Demographic Characteristics, Education, Language and Religion. Key Findings. Available at http://www.singstat.gov.sg/pubn/popn/c2010sr1/findings.pdf

Stinson, M., Silver, R.E., Amasha, S.A., Pak, S., and Wright, S. (2010). CIEPSS Handbook of Research Protocols: Volume 1. Singapore: Centre for Research in Pedagogy and Practice, National Institute of Education. Available at http://hdl.handle.net/10497/3725

Tan, C., \& Ng, P. T. (2007). Dynamics of change: decentralised centralism of education in Singapore. Journal of Educational Change, 8(2), 155-168. 
Silver, Curdt-Christiansen, Wright and Stinson

Working through the layers

Towndrow, P., Silver, R. E., \& Albright, J. (2010). Setting expectations for education innovations. Journal of Educational Change, 11, 425-455. 


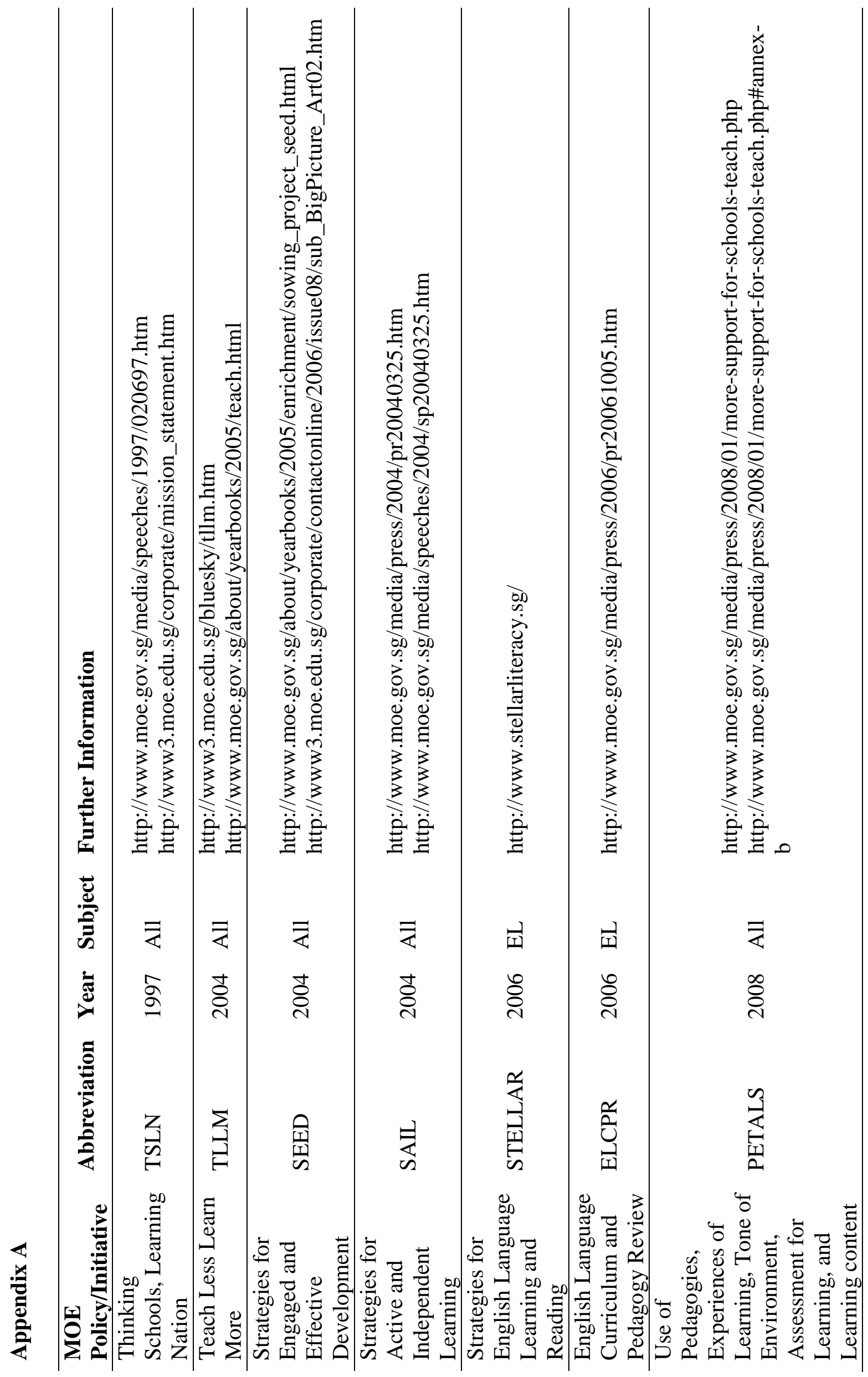




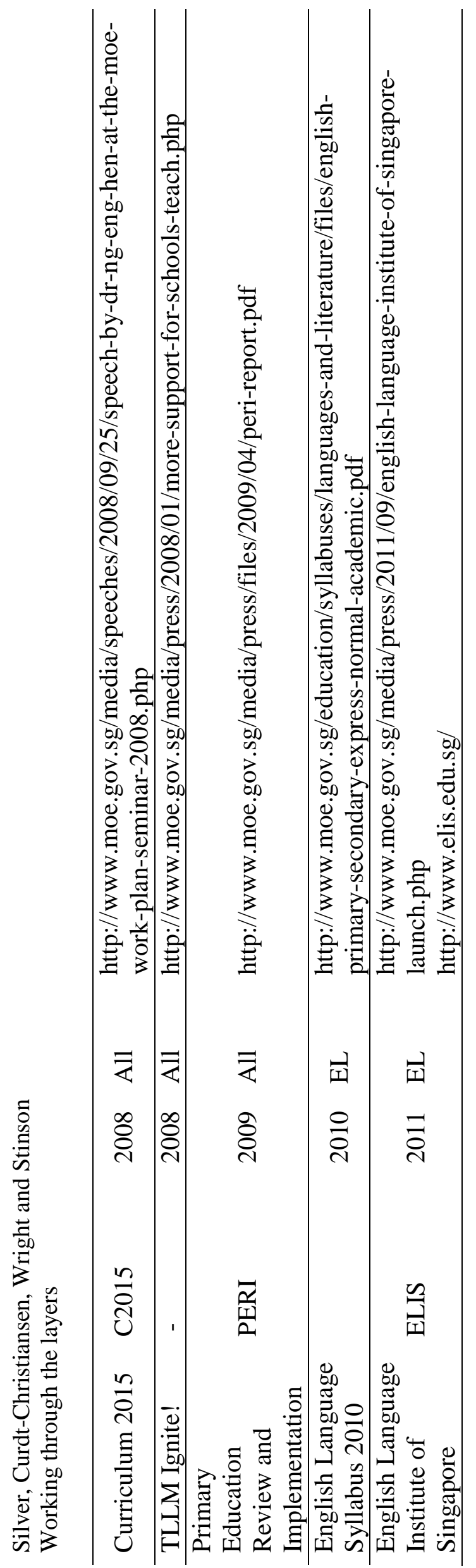


Silver, Curdt-Christiansen, Wright and Stinson

Working through the layers

\section{Figure 1. Overview of TSLN Policy Enactment}

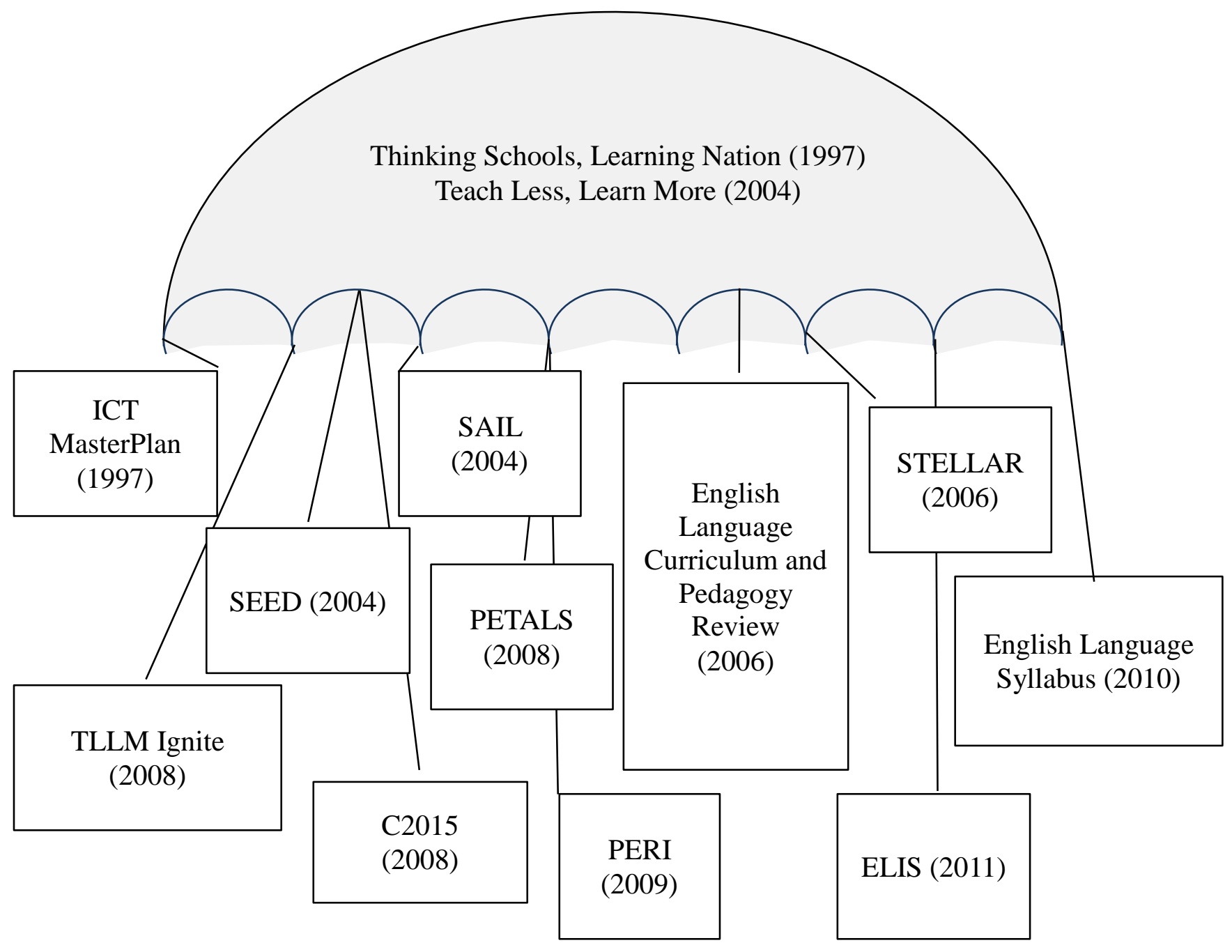

